\title{
Édipo rei: a formação do homem para a polis
}

Oedipus king: preparing man for the polis

José Joaquim Pereira Melo*

Universidade Estadual de Maringá

Renan Willian Fernandes Gomes**

Universidade Estadual de Maringá

Resumo Pretende-se, com este texto, discutir a proposta de formação do homem grego para a polis, conforme se entende que foi expressa por Sófocles em Édipo Rei. Nessa peça, ainda que de maneira não intencional, o autor apontou o ideal de homem que, em sua perspectiva, poderia vir a responder às necessidades da sociedade helênica do seu tempo, a qual, dividida entre o mito e a razão, contava com um homem em conflito que precisava de direcionamento. Sófocles, por meio de seu protagonista, representou a conduta que considerava ideal e, ao fazê-lo, abriu para o público uma possibilidade de reflexão e discussão a respeito das transformações econômicas, sociais e políticas de seu tempo. Assim, ele criou um heroi que, para além do papel do cidadão, constituiu-se como um modelo de formação diferente do consagrado pelo período arcaico.

PALAVRAS-CHAVE: Sófocles, Homem, Formação, Polis.

Abstract Having Sophoclean play Oedipus King as a frame of reference, the purpose of this paper is to discuss the educative proposal conceived to the Greek Man as preparation for life in the polis. Although not intentionally, Sophocles pointed out an ideal of Man which, in his perspective, would fulfill Greek societal demands of that time. Such society was divided between myth and rationality and, as a result, Man found Himself in conflict and lacking direction for His life. Given that, Oedipus' character represented the ideal behavior of that society, and it also made it possible for citizens to reflect and to discuss social, economic and political transformations taking place at that period. Thus Sophocles came up with a hero who was an educational model and a citizen's as well. Furthermore, such hero differed from that one of the archaic Greek thought.

KEYWORDS: Sophocles, Man, Education, Polis. 


\section{Considerações iniciais}

No século V, o imaginário grego passava por uma grande reorganização, tanto na maneira de o homem enxergar a sociedade quanto na de entender o papel dos deuses em sua vida. Uma mudança fundamental nesse momento: a antiga sociedade patriarcal cedia espaço para aquilo que seria uma sociedade democrática, orientada pela razão, que se apresentava como uma contrapartida ao pensamento mitificado expresso nos ritos familiares.

O rompimento com a antiga ordem social foi um processo complexo que requisitou do homem o abandono do comportamento, outrora passivo, em favor de um mais ativo/incisivo (CAMERON, 1968), tendo em vista um bem que extrapolava os limites do seu grupo familiar. Em face dessa complexidade, não houve de imediato uma ruptura com a antiga ordem social: em muitos aspectos, esta se manteve presente no cotidiano grego.

O exercício do pensamento racional não exigia que o grego se desvinculasse totalmente de suas tradições gentílicas e também não implicava um desrespeito aos deuses. O que aconteceu, pode-se pensar, foi a adoção de uma postura menos passiva em relação ao que estava ocorrendo na organização da cidade-estado (NAGEL, 2006), ou seja, na nova ordem econômica, social e política da democracia, que diminuía consideravelmente o espaço que, outrora, era privilégio dos chefes dos antigos clãs aristocráticos.

Assim, esse novo proceder, a rigor, implicava a necessidade de um fenômeno formativo diferente daquele registrado nos cantos de Homero. Ao passo que estes enalteciam um heroi perfeito, voltado para as virtudes e qualidades inerentes ao homem guerreiro; o que se requeria, no novo momento, era um homem que se dedicasse à reflexão, promovida pela razão e pelo pensar filosófico.

A organização da polis, além de novas demandas econômicas, promoveu mudanças de costumes e práticas que até então pareciam imutáveis. Nesse cenário, em que as transformações materiais exigiam uma nova forma de viver, o homem deveria se colocar em uma posição cada vez mais questionadora, buscar respostas para perguntas nunca antes feitas e, como resultado, formular conceitos outrora inexistentes também (ADKINS, 1972).

Destarte, formava-se um homem que encontraria na racionalidade, na indagação e no questionamento a explicação para sua vida e para o mundo à sua volta. A preocupação com seus comportamentos e atos e com o que deles resultava passou a ser objeto de sua reflexão. Isso porque os deuses já não podiam ser considerados culpados por esses mesmos atos e comportamentos (KNOX, 2002), ou seja, o homem começava a assumir a responsabilidade pelo seu destino.

Viver na polis foi fundamental para a efetivação do novo ordenamento que surgia naquele século. O compartilhamento das experiências, incertezas, dúvidas e dores serviu de fio condutor para o pensar coletivo na busca de soluções 
também coletivas. Passou a ser candente para o grego construir e transformar, com base em seus próprios referenciais, os quais tinham pouca relação com os deuses.

A literatura produzida, nesse período, é expressão desse cenário, especialmente a obra de Sófocles (497-405 a.C.), Édipo Rei, ${ }^{1}$ particularmente, que retrata as transformações que esse homem vivenciava: o heroi diferenciado, que Sófocles representou, corresponderia a um projeto de formação para educar o homem de seu tempo.

Por meio de Édipo, o autor busca por à luz o que entendia como os mistérios da vida: agir com base na razão e na reflexão pressupunha não aceitar com passividade aquilo que era determinado ao homem pelos caprichos dos deuses (FERREIRA, 1992). Com isso, Édipo é entendido como um homem característico de um mundo em transformação/transição; ou seja, um homem que vivia o processo no qual uma antiga ordem social em decadência cedia espaço para uma nova ordem social que se firmava.

Em outras palavras, é possível depreender no heroi sofocliano resquícios da antiga maneira de se viver que estava desaparecendo e cedendo espaço para a polis.

\section{Édipo Rei: expressão do embate entre duas formas de vida}

Em Édipo Rei, Sófocles apresenta ao público grego um embate entre os costumes daquela sociedade no período de transição e ressalta os reflexos desse conflito na vida citadina. Mostra a decadência do ideário mítico ao por em tela um homem que não é mais orientado pelo querer olímpico, mas, sim, pela razão, um homem que passa a organizar a sociedade democrática, cuja preocupação é o bem comum.

Em síntese, Sófocles representa um homem que assume a sua historicidade. Édipo, personagem central da peça, pautando suas ações na racionalidade e na preocupação com o bem coletivo, representa um homem ideal para a polis, ou seja, o homem necessário a esse tempo.

O tragediógrafo escolheu esse tempo e as indagações a respeito dele para ambientar sua ação dramática, levando-nos a considerar que o mito de Édipo é, por excelência, a expressão da transição social e do processo de elaboração de novos conceitos e de tomada de novas posturas (KITTO, 1958). O drama tem como base estrutural uma comparação metafórica entre dois mundos: aquele cujo pensamento se resumia na religião e na autoridade patriarcal e aquele que se distanciava dessa autoridade e colocava nas mãos do homem o poder para reger sua própria existência.

Nessa forma de construção literária, concomitante ao conteúdo artístico, é possível identificar uma preocupação formativa, por meio da qual Sófocles instigava o homem a pensar sobre o que sua sociedade precisava naquele momento, bem como sobre o papel que lhe caberia como cidadão, qual seria o seu dever em favor da ordem social que deveria reinar na polis. 
Os mitos, utilizados pelas tragédias como mote, não contêm unicamente os resquícios da antiga organização social, mas também, expressam a luta entre concepções/visões de mundo que, por suas orientações, são antagônicas: razão versus mito, homens versus deuses, polis versus génos, democracia versus lideranças familiares (SEGAL, 1994).

Nas palavras de Bernard Knox (2002), Édipo é um protagonista muito diferente do heroi arcaico: é um homem de visão científica. Isso porque Sófocles dotou seu heroi de um espírito investigativo, voltado para a busca da verdade, e de uma conduta ativa, que não descansava em desnudar aquilo que estava oculto. Esse caráter de Édipo somado à sua posição hierárquica na peça (governante) abre um caminho para se discutir qual posição deveria, um governante ideal, tomar diante das mudanças de então.

Tal questionamento crítico é próprio de uma formação cujo objetivo maior é a reflexão em prol da sociedade. O grego, que assistisse à peça, passaria a filtrar as ações dos personagens de modo a compará-las, examiná-las sob o crivo de sua experiência humana (DAWE, 1973) e, quem sabe, tomar novos posicionamentos, pensar de outra maneira, enfim, adaptar-se ao mundo que assim o exigia.

Soma-se a isso o fascínio despertado no público por Édipo, por suas qualidades de destemido, corajoso, persistente, tenaz no que se propunha realizar: no caso, descobrir as causas que penalizavam Tebas, ${ }^{2}$ já que isso seria a libertação da sua polis. As qualidades desse homem ideal, pode-se inferir, passavam a ganhar destaque e lugar naquele tempo como projeto de formação, pois, ao se identificar com o seu representante heroi, o homem poderia adotar, para sua vida, os mesmos procedimentos e orientações, passando a ter sempre em conta o bem de todos.

O agir do heroi sofocliano é o resultado de um espírito crítico e dos feitos intelectivos de uma geração sofista, de homens preocupados com a ciência e a com a filosofia (KITTO, 1958). Com esse referencial, a trama sofocliana distancia Édipo dos deuses, os quais, outrora, davam, ao espetáculo trágico, fôlego para o desenvolvimento das peripécias, tão caras ao sucesso das peças. Édipo, a cada nova descoberta, aciona a ação de modo a refletir uma vida ativa em sociedade, promotora de mudança de cursos.

Esse servir à cidade em consonância com os interesses públicos, a exemplo de Édipo, era responsabilidade de todos os que viviam na cidade-estado. Por esse motivo, a ênfase recaía sobre o interesse público. Sófocles atribuiu a seu heroi esse interesse, não somente porque ele representava um governante, mas também, porque representava o homem daquele tempo histórico (KNOX, 2002).

Com base nesses referenciais orientadores da polis, espaço no qual o homem se realizava em sua cidadania, rechaçava-se todo e qualquer ataque que pusesse em risco sua plenitude. Por isso, em Édipo Rei, colocando-a em cena, expressando-a como uma instância que era atormentada por força que lhe era estranha, Sófocles convocava o público, pelo impacto, a pensar em instrumentos 
para preservá-la e protegê-la nas adversidades (ANDERSON, 1965). Por meio de seu protagonista, Sófocles apontou para o homem da polis qual deveria ser sua atitude, quer em termos de participação na vida pública quer em termos de enfrentamento da crise, mesmo que isso lhe custasse sofrimentos, a exemplo de Édipo. ${ }^{3}$

\author{
ÉDIPO \\ Ai de mim! Ai de mim! As dúvidas desfazem-se! \\ Ah! Luz do Sol. Queiram os deuses que esta seja \\ a derradeira vez que te contemplo! Hoje \\ tornou-se claro a todos que eu não poderia \\ nascer de quem nasci, nem viver com quem vivo \\ e, mais ainda, assassinei quem não devia!
}

(SÓFOCLES, vv. 86-92).

Ao descobrir que ele mesmo tinha sido o autor do crime que trouxera a peste que dizimava a população de Tebas, Édipo, ainda que fragilizado, assumiu a culpa e as consequências em nome do que sempre defendeu como o bem da sua polis, inclusive desde os primeiros momentos em que se dirigiu a ela, quando decifrou o enigma da Esfinge. ${ }^{4}$

Assim, por mais sofrimento que isso acarretasse, mesmo sendo rei e a despeito do seu interesse pessoal, de forma decidida e heroica, Édipo assumiu a pena em favor do bem coletivo (ADKINS, 1972). Isso leva à interpretação de que, mesmo que sua condição real pudesse isentá-lo da culpa e da punição, seu dever para com a cidade e seus concidadãos era maior. Corporificada em Édipo, que em nenhum momento, hesitou em fazer o necessário para o bem geral, fica representada a consciência de cidadania apropriada àquele momento.

Em outros termos, em sua decisão, Édipo não se afastou dos deveres do homem para com a sociedade, assumindo seu destino, cumprindo os deveres e as exigências requisitadas pela polis democrática. Agindo em prol do bem-estar público, correspondendo ao projeto ideal de formação do legislador, ele deixou um exemplo de cidadania aos demais cidadãos: para além de questionar e investigar, ele tomava para si a tarefa de defender, sob qualquer pena, o bem maior da cidade.

Com base na interpretação de Sófocles, é possível considerar que, com a polis, o espírito helênico passou a dar importância à luta coletiva, o que implica que esta se sobrepunha aos interesses individuais. A construção da democracia, o exercício da racionalidade e o pensar filosófico assim o exigiam (LATTIMORE, 1964). Nesse sentido, também a orientação que Sófocles atribuiu a Édipo converteu-o em um exemplo de modelo formativo.

Assim, a Atenas sofocliana assume um perfil ideal de polis e, por extensão, o seu cidadão deveria corresponder ao que se propunha como um homem ideal, apto a transitar pelos novos tempos que se colocavam para a sociedade grega. $\mathrm{Ou}$ 
seja, tal como Édipo, o homem da polis deveria assumir uma postura reflexiva, cujos resultados deveriam estar voltados ao serviço da cidade (ADKINS, 1972).

Em Édipo Rei, Sófocles expressa a relação que deveria se firmar entre o cidadão e a cidade, posto esta ser o referencial de realização pessoal e coletiva. Daí que, para ele, o sofrimento da cidade seria o sofrimento dos homens que a constituíam.

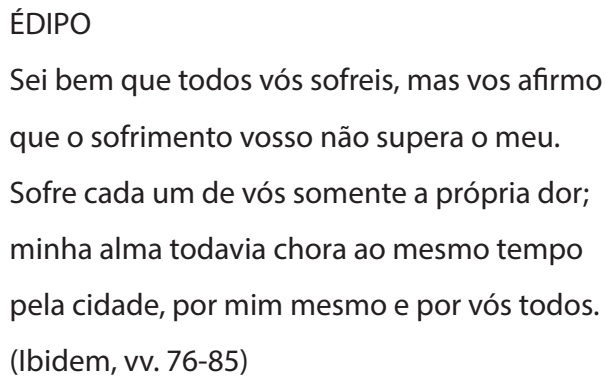

Vale reiterar que o poeta mostra Édipo na condição de legislador e governante, interessado não no bem individual, mas na coletividade. É isso o que justifica que sua pena tenha sido comutada na atitude extrema de vazar os olhos. O cidadão rei, em um exercício democrático, curvava-se a um interesse maior que era o da polis.

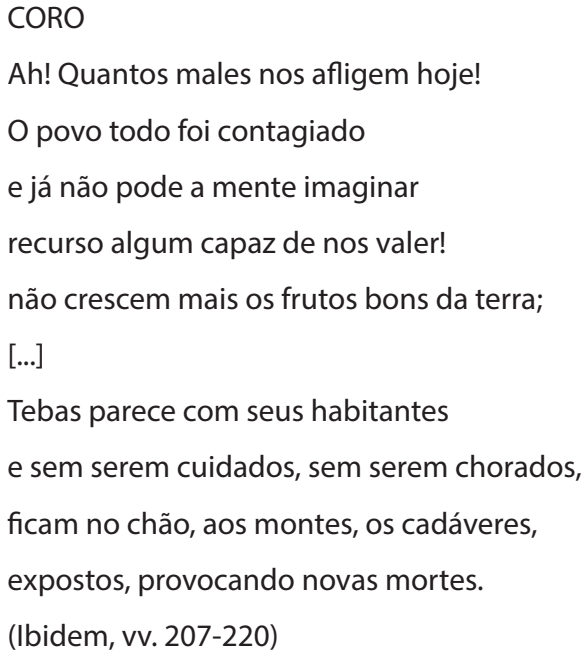

Era, no seio da polis, que se completava o cidadão: ele compreendia as suas necessidades e lutava para que elas fossem supridas. Essa preocupação o projetava em oposição à tradição gentílica, fundada na posse da terra, na herança ou no berço aristocrático (JAEGER, 1995), o que se constituiu em grande diferencial no mundo grego, em uma experiência única em toda a Antiguidade. Ao viver na cidade e pela cidade, os gregos a concebiam como uma unidade de caráter único, natural e justo, na qual a prática democrática grega chegava à sua plenitude 
(BOWRA, 1967). Tal forma de organização não se enquadrava em outros povos, considerados como bárbaros.

O heroi da polis: entre as vontades olímpicas e a responsabilidade pelo próprio destino

A racionalidade demonstrada por Édipo, ao solucionar o problema que assolava Tebas, além de se relacionar à responsabilidade que ele deveria assumir como governante, marcava também sua relação de responsabilidade para com sua cidade. Édipo exemplifica o homem requisitado pela polis, ou seja, o homem de ação, que chama para si a sua historicidade.

ÉDIPO

É horrível! Temo que Tirésias, mesmo cego

tenha enxergado, mas ainda quero ouvir

uma palavra tua para esclarecer-me.

(lbidem, vv. 892-894)

E prossegue:

ÉDIPO

$[\ldots]$

E o que é pior, fui eu, não foi outro qualquer, quem pronunciou as maldições contra mim mesmo.

Também maculo a esposa do finado rei

ao estreitá-la nestes braços que o mataram!

Não sou um miserável monstro de impureza?

(Ibidem, vv. 984-985)

Importa destacarque o comportamento deÉdipo, em relação ao problema que lhe era colocado, abria possibilidades de discussão sobre os caminhos para a formação de um novo ideal de homem, que não guardaria relação com o processo formativo do período arcaico. Isso pode ser depreendido da voz que Sófocles dá a Jocasta sobre o possível caráter falível das previsões dos deuses.
JOCASTA
Não há razões, então, para inquietação;
ouve-me atentamente e ficarás sabendo
que o dom divinatório não foi concedido
a nenhum dos mortais; em escassas palavras
vou dar te provas disso. Não direi que Febo,
mas um de seus intérpretes, há muito tempo 


\begin{abstract}
comunicou a Laio, por meio de oráculos, que um filho meu e dele o assassinaria; pois apesar desses oráculos notórios todos afirmam que assaltantes de outras terras mataram Laio há anos numa encruzilhada.
\end{abstract}

$[\ldots]$

Falharam os oráculos; o próprio deus evidencia seus desígnios quando quer sem recorrer a intérpretes, somente ele. (Idibem, vv. 848-870)

Ao tratar a situação edipiana dessa forma, Sófocles leva à discussão da emergência de um pensar racional, próprio da nova, organização que se instaurava na sociedade grega, o que, por sua vez, pressupunha um novo padrão de comportamento em relação a essa mesma sociedade. Papel significativo nesse processo caberia ao fenômeno formativo, cujo ponto de largada seriam as reflexões que as peças poderiam suscitar no público (LLOYD-JONES, 1965).

Com seu enredo, o que Sófocles propunha que se colocasse na ordem do dia era a busca pela justa medida entre uma crença arcaica, tida como imutável, e os novos valores, que se descortinavam com os novos tempos e tinham a racionalidade, a democracia e a filosofia como seus fundamentos. Era o querer humano em oposição aos desígnios divinos: o homem rompia com as vontades olímpicas para se responsabilizar pelo seu destino, para assumir a direção de sua própria vida.

A habilidade no manuseio das armas já não era suficiente para a garantia da vida em sociedade; outras habilidades eram requeridas para a vida na polis, a exemplo da reflexão, que favorecia que o homem chegasse a conclusões que seriam próprias daquele que buscava alcançar a autonomia. É o que Sófocles expressa com os comentários de Édipo quando decifrou o enigma da Esfinge.

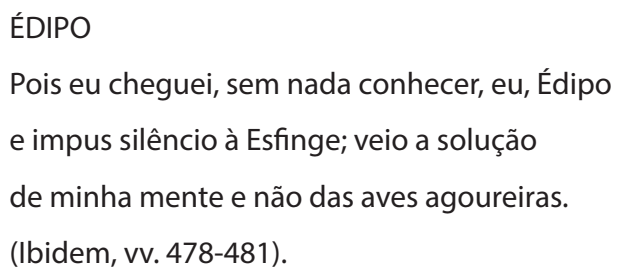

O raciocínio edipiano contrapõe-se aos augúrios divinos próprios dos mitos. Afinal, o homem tomava para si a responsabilidade pelos seus atos, quer os relacionados à medida quer à desmedida, o que, de uma forma ou de outra, afetava a sociedade. O que Sófocles colocou no debate foi a valorização do pensar e das atitudes humanas, mas sem romper totalmente com o comum e o aceito pela tradição. 
No entanto, em Sófocles, essa forma de o homem se orientar, de assumir sua historicidade, pressupõe a responsabilidade plena, ou seja, os erros e acertos são exclusivamente do homem, que não pode mais se isentar deles escudando-se nos deuses. Com isso, fica evidente que agir por meio da reflexão e da racionalidade implica tanto a plenitude humana quanto sua falibilidade.

\author{
ÉDIPO \\ E o pior, fui eu, não foi outro qualquer, \\ quem pronunciou as maldições contra mim mesmo.

Isto posto, é possível afirmar que Sófocles discutiu um novo modelo de formação, expressando-o em Édipo. Tendo em vista as transformações que se consolidavam naquela sociedade, o homem deveria ser formado para o exercício democrático, questionador, crítico, cuja grande orientadora seria a razão. Édipo corresponderia ao modelo formativo idealizado por Sófocles para a polis.

\title{
Considerações finais
}

Concluímos, conforme considerações feitas no decorrer do texto, que, em decorrência das transformações de seu tempo, Édipo foi o modelo de formação proposto por Sófocles para se viver em consonância com os valores inerentes a polis.

Evidenciando as fraquezas de seu heroi, mas destacando suas virtudes, Sófocles propôs uma nova forma de pensar o homem e a sociedade, cujas transformações requisitavam uma nova orientação: o exercício racional, democrático e filosófico pressupunha um homem de ação diante dos problemas que se apresentavam.

Assim, ao assumir sua historicidade e chamar para si as responsabilidades pelos seus atos, mesmo quando investido da autoridade de governante, Édipo deixa uma lição para toda a sociedade: indistintamente da posição social, cada um deve enfrentar as consequências de suas ações em favor da polis. Ao propor essa maneira de viver, comportar-se e agir em sociedade, a dramaturgia sofocliana, mesmo que de forma não intencional, converte-se em instrumento formativo do homem a quem era destinado. 
Desse modo, ao se propor a refletir com sua arte, ao expressar as dores e as dificuldades de seu tempo, as novas formas de se posicionar diante de uma sociedade em conflito, o que é próprio dos períodos de transformação social, Sófocles se expressa quase como um "pedagogo". Quando ele se propôs ensinar seu público a pensar a sociedade em que vivia e para a qual vivia, deu ao sofrimento trágico, que já era conhecido do homem grego por meio do mito, novos contornos: um caráter formativo, no qual a arte dava sua contribuição para a elaboração de um modelo de homem apresentado como ideal, a formação pelo exemplo, mesmo que, para isso, fossem utilizadas as peripécias e dores trágicas.

\section{Referências}

ADKINS, M. V. Moral values and political behavior in ancient Greece. London: Cambridge Press, 1972.

ANDERSON, M. J. Classical drama and its influence. London: Cambridge Press, 1965.

BOWRA, C. M. A experiência grega. Lisboa: Arcaída, 1967.

CAMERON, A. The identity of Oedipus the King. New York and London: 1968.

DAWE, R. D. Studies on the text of Sophocles I. Leiden: Cambridge Press, 1973.

FERREIRA, J. R. A Grécia antiga: sociedade e política. Lisboa: Edições 70, 1992.

JAEGER, W. Paidéia: a formação do homem grego. Trad. Artur M. Parreira. São Paulo: Martins Fontes, 1995.

KITTO, H. D. F. Sophocles, dramatist and philosopher. London: Oxford Press, 1958.

KNOX, B. Édipo em Tebas. Trad. Margarida Goldsztyn. São Paulo: Perspectiva, 2002.

LATTIMORE, S. P. G. T. Story patterns in Greek tragedy. London: 1964.

LLOYD-JONES. O mundo Grego. Trad. Waltensir Dutra. Rio de Janerio: Zahar, 1965.

NAGEL, L. H. Dançando com os textos Gregos: a intimidade da literatura com a educação. Maringá: EDUEM, 2006.

SEGAL, C. O ouvinte e o espectador. In: VERNANT, J-P (Org.). O homem grego. Trad. Maria Jorge Vilar de Figueredo. Lisboa: Editorial Presença, 1994. p. 173-198.

SÓFOCLES, Édipo Rei. In: A Trilogia Tebana. Trad. Mario da Gama Kury. 9. ed. Rio de Janeiro: Zahar, 2001.

\section{Notas}

\footnotetext{
1 Peça provavelmente representada em 430 a.C., cujo personagem central Édipo, mesmo antes de nascer, é condenado pelos deuses a matar seu pai Laio e casar-se com a sua mãe, Jocasta, reis de Tebas. Informado disso por um Oráculo, Édipo decide fugir da cidade, onde acreditava morar com seus pais, Pôlibo e Mérope, reis de Corinto, para assim evitar que se cumprisse a maldição. Édipo vai para Tebas. Em seu caminho, em uma encruzilhada, é afrontado por integrantes de uma comitiva real. Édipo reage à agressão e acaba matando-os, inclusive Laio, restando apenas um que conseguisse fugir. Ao entrar na cidade de Tebas, depara-se com um problema que atormentava a cidade. Qual seja: uma Esfinge, monstro que tinha a cabeça e o busto de mulher, as patas de leão, o corpo de cão, cauda de dragão e asas como as das Hárpias, que propunha um enigma aos seus cidadãos, quem não o decifrasse, era por ela sacrificado. Édipo enfrenta e decifra o enigma. Como recompensa, é coroado rei e desposa Jocasta,
} 
a viúva de Laio, cumprindo-se, assim, o parricídio e o casamento com a mãe, conforme as previsões do Oráculo.

${ }^{2}$ A cidade de Tebas, por conta do assassinato de Laio, se encontrava sofrendo devido a uma praga. Édipo, como rei, é convocado a salvá-la e é informado pelo Oráculo que a única maneira de livrar a cidade é descobrir o assassino do antigo rei.

${ }^{3}$ Ao descobrir que ele mesmo era o responsável pela praga da cidade, Édipo se autopune, fazendo os próprios olhos.

${ }^{4}$ Quando jovem, Édipo decifrou o enigma (Qual é o animal que tem quatro patas de manhã, duas ao meio-dia e três à noite?) da Esfinge que assolava a cidade de Tebas.

* Professor Doutor Universidade Estadual de Maringá, Centro de Ciências Humanas Letras e Artes, Departamento de Fundamentos da Educação. Maringa, Paraná - Brasil.

** Professor Mestrando do Programa de Pós-Graduação em Educação pela Universidade Estadual de Maringá. Maringa, Paraná - Brasil.

\section{Correspondência}

José Joaquim Pereira Melo - Universidade Estadual de Maringá, Centro de Ciências Humanas Letras e Artes, Departamento de Fundamentos da Educação. Av. Colombo, 5790, Jd Universitário, CEP: 87020900 - Maringa, Paraná - Brasil.

E-mail:jjpmelo@hotmail.com - rw_gomes@hotmail.com

Recebido em 30 de outubro de 2012

Aprovado em 09 de julho de 2013 
